\title{
Visually negotiating hegemonic discourse through Photovoice: Understanding youth representations of safety
}

Nick Malherbe, Shahnaaz Suffla, Mohamed Seedat and Umesh Bawa

\begin{abstract}
Despite the immense communicative potential of visual methodologies, surprisingly few community-based research studies have meaningfully considered participants' visual meaning-making processes. When working with youth participants from contexts with which researchers are unfamiliar, the use of visual methodologies and analyses is able to transcend much of the developmental and cultural barriers to communication that are inherent in many linguistically focused research methods. By employing a visual discourse analysis on six photographs captured by Ethiopian youth in a Multi-Country Photovoice Project on youth representations of safety, this study aims to showcase the value of analysing participants' use of 'alternative' visual discourses. It was found that participants drew predominantly on two discourses, Humanising Capital and Unity, both of which resisted a number of Western hegemonic discourses surrounding youth constructions of safety. Participants' visual constructions served as a meaningful mode of communication, as well as a relevant approach to facilitating youth ownership of meaning-making processes within community-based research.
\end{abstract}

\section{Introduction}

Due largely to epistemological uncertainty regarding how visual images should be analysed and coded, few community-based research studies have harnessed participants' visual meaning-making processes (Banks, 2001). By transcending a number of cultural and developmental barriers to expression which are inherent in much linguistically focused research, visual methodologies and analyses serve as an important means of generating alternative discourse within social science research. By analysing the images captured in the Ethiopian component of a Multi-Country Photovoice Project on youth representations of safety, this article focuses on how visual meaning-making processes - rather than the linguistic-based knowledge production which pervades social science research - allow youth the space to both uphold and resist hegemonic discourses surrounding constructions of safety in a culturally and developmentally sensitive manner.

The article begins by locating visual methodologies within social science research. Following this, we examine the broader use of discursive visual constructions, as well as photographs, as discursive meaning-making tools. The Photovoice method and the 
Multi-Country Photovoice Project are then explained. The next section examines the manner in which young people are able to resist and uphold visual discourses, specifically those relating to safety. Finally, the study results and the advantages of visual discourses are presented within the context of broader discourses on safety.

\section{Visual methodologies within social science}

As social science is a discipline traditionally concerned with linguistic text, visual images are ordinarily reduced to illustrative devises, seldom forming any kind of analytical site (Bell, 2008). The analysis of visuals within this sort of research tends to be unexpected, secondary and superfluous (Rich and Chalfen, 1999). Social science studies that do consider images as having analytical value are generally underpinned by sociological or anthropological epistemologies (Banks, 2001), with relatively few situated within psychological frameworks.

It is, however, crucial that visual text is understood as an independent mode of meaningmaking. Indeed, if language is an organised set of signs and symbols which fulfil particular, contextually bound functions, images, with their underlying organisation, make use of a number of semiotic resources to convey meaning. In this regard, images contain a visual language which can be read, or analysed. Visuals do not convey more or less knowledge than the written word. Rather, they are able to convey different knowledge (MacDougall, 2011), and it is this different knowledge which is largely ignored - and therefore lost - within social science research. When harnessing the communicative potential of visual images, it is important to not under-consider the social context in which the image is created. As a means of privileging the context as well as the intersectional nature of visual meaning-making processes, one may turn to the discourses on which visual texts draw.

\section{Visual discourses}

Sartre (2006) conceptualises images as reflecting consciousness, meaning that the image is not understood with respect to that which it depicts, but rather that which it allows the viewer to experience. Visual construction and effectiveness are alluded to in this regard, and the image is awarded greater autonomy than is typical within the social sciences (Newbury, 2011). Various discourses then act to negotiate the culturally and historically bound meanings which viewers attribute to images (Banks, 2001).

The verbal and written modes of expression that pervade much social science research have limited access to the emotional and symbolic facets of experience which are mediated by visual texts (Niesyto et al., 2003) and may form a communicative barrier if participants are not fluent in a study's language of instruction. Furthermore, participants may be unfamiliar with various cultural conventions which accompany the linguistic facets of language (Rich and Chalfen, 1999).

The extent to which people are able to resist the various hegemonic discourses in which they are immersed is not always clear (Scott et al., 1998). The radical openness of visual expression may provide participants with a meaningful platform through which their use of discourse can be meaningfully analysed. As visual research methods are less standardised than 
linguistic approaches, they are typically considered 'messy'. However, it is this messiness which allows participants the ability to transcend the limitations of more structured verbal communication (Sanon et al., 2014). Although visual methodologies are bound by particular rules, their unstandardised mode of communication allows for a radical kind of freedom and simplicity of expression. Participants may feel capable and at ease in expressing themselves visually, especially to cultural outsiders. In this regard, photography is a particularly effective means of visual communication (Wang and Burris, 1997).

\section{Photographs as intersectional sites of visual discourse}

Although there is no grammatically bound photographic language, like all visuals, photographs are inscribed with a visual language (Rich, 2004). It is therefore not the photograph per se that communicates visual meaning, it is the viewer's experience of the image which does this and - as is the case with linguistic texts - it is the viewer who attaches interpretative discursive meanings to visual images (Harrison, 2004). Photographic texts are then etched within photographic discourse, which engages the image in other discourses. The photograph may thus be considered as an intersectional discursive site, where a variety of texts overlap.

The analytic implications of photographs must be addressed so that issues of clarity and cohesion, which tend to plague visual research, are partially addressed (Rich and Chalfen, 1999). Images are not understood as uncoded replicas of reality or individualistic modes of expression performed by children or artists (Kress and Van Leeuwen, 2006). Similarly, visual images should not be interpreted on the basis of their relation to verbal texts. Indeed, both verbal and visual discourses are able to convey the same message; however, they do so independently and on their own terms. Photographs are vehicles of communication which are able to engage viewers as witnesses to specific spatial locations (Jopson, 2009) and in this regard are considered to be building blocks of meaning-making that locate people's priorities at a particular historical moment (Wang, 2006). As cultural domains are intrinsically visual and can perhaps be grasped most effectively through visual representation (Banks, 2001), it is suggested that photographs are able to accurately illuminate that which is invisible to cultural outsiders and unclear within linguistic communication (Suffla et al., 2012).

\section{Youth and discourse}

Despite being immensely useful in examining issues that affect their well-being, young people's expression is continually marginalised within society as well as research studies. The diminished, or systematic, weakening of youth voices is compounded when living in conditions of poverty, with reduced familial and financial support acting to limit young people's ability to meaningfully engage with pertinent issues in their lives (Wang, 2006). Furthermore, the wealth of analyses concerning linguistic expression has resulted in researchers ascribing spoken or written language as the primary means through which youth are to express themselves, ignoring communicative difficulties relating to cultural differences and developmental stages. 
It is thought that adolescents have higher-order cognitive skills and have a greater capacity to engage with community issues than younger children (Gant et al., 2009). Older children are therefore able to produce, re-produce and resist the various discourses in which they are immersed. Despite this, linguistically-centred discourse analyses are generally employed with older adolescents or, more commonly, adults as it is thought that younger children's diminished cognitive development may hinder their ability to effectively communicate (Spjeldnaes et al., 2011). However, young children should not be ignored within critical discursive research because researchers are unwilling to provide a mode of expression which does not have an accompanying 'direct fit' linguistic analysis.

It is therefore imperative that youth, especially those who are immersed in a culture which differs from that of researchers, be provided with a means of communication that is tailored to their developmental, cultural and linguistic positionality, rather than that which lends itself to a standardised linguistic-based analysis. The quality and the ease of youth expression are paramount when entering discussions on issues such as youth constructions of safety, which have direct effects on young people but continue to be dominated by adult-centric discourses. Visual methodologies, specifically the use of photography, provide youth with an ideal, accessible and simple expressive language. Researchers are then able to analyse the manner in which youth engage with various hegemonic and alternative discourses. This study aims to argue for a visual-based method (Photovoice) and analysis (visual discourse analysis (VDA)) which accommodate effective youth expression and allow participants to assume ownership of the research process.

This study is concerned with analysing children's ability to uphold or challenge various hegemonic discourses related to safety in their community. Popular and academic discourses have acted to individualise issues of safety (Backett-Milburn and Harden, 2004), where children are thought to be either victims or perpetrators who need to be protected or controlled. Such discourse does not construct children as autonomous or engaged social actors (Suffla et al., 2012). Rather, they are understood as passive figures who are vulnerable to their surrounding environments, in need of constant adult protection, and to be led by adult constructions of safety. This set of safety-related discourses is located within and emerges from the notions of child innocence and vulnerability and is therefore exclusive to youth, with adult constructions of safety occupying a distinct set of discourses (Moran et al., 1997).

Although youth constructions of safety are mediated through these adult-centric discourses (Scott et al., 1998), Harden et al. (2000) found that such discourses do not necessarily afford an effective means of understanding children's interpretations of safety. In illustrating this, the researchers highlight that in the United Kingdom 'stranger-danger' was found to be the most common theme within child safety constructions among parents, despite accidents being responsible for far more child-related deaths and injuries. Youth discourses on safety cannot continue to be understood via adult-mediated dialogue. The voices of children are central to developing a nuanced understanding of safety as it is construed by young people, 
and require a relevant and youth-centric medium of expression for their articulation and recognition.

This study draws on data from the Ethiopian component of the Multi-Country Photovoice Project. Initiated in 2011 by the University of South Africa's Institute for Social Health Sciences and its South African Medical Research Council - University of South Africa Violence, Injury and Peace Research Unit, the project invited participants to photograph things, places and people that make them feel safe and unsafe in their respective communities. The project aimed to highlight youth representations of safety within marginalised communities in South Africa, Mozambique, Zambia, Uganda, Egypt and Ethiopia. Participants' voices were harnessed as a means of initiating engagement in critical dialogue with adults, as well as leading in a number of social justice campaigns. Numerous photographic exhibitions celebrating the participants' meaning-making processes were held in each country (Suffla et al., 2014).

\section{Method}

\section{Participants}

A total of 16 participants - 8 males and 8 females - between the ages of 11 and 14 years participated in the study. The participants were from a low-income community. They spoke either English (the major foreign language taught in schools) or Tigrinian (spoken by $5.5 \%$ of the total population) and resided in the historical city of Axum, located in northern Ethiopia (Central Intelligence Agency (CIA), 2013). The participants' age and language were not considered to represent a significant communication challenge as the study made use of a visual mode of expression. The study situated participants as active social agents who are able to construct their own meaning.

\section{Data collection}

This study utilised Photovoice as a method of data collection. Photovoice involves providing cameras and some basic photography training to disenfranchised members of a community, who then take photographs to represent a particular social or health issue (Wang and Burris, 1997). In this study, as indicated earlier, the topic was 'Things, places and people that make me feel safe and unsafe in my community'. Later, participants are interviewed, individually and as a group, about their photographs. Through the Photovoice methodology, action and reflection occur together in the hope of igniting a sense of advocacy within participants, who may then work towards engaging with various community concerns (Carlson et al., 2006).

The visual data, in the form of participants' photographs, form the principal site of analysis, with the linguistic narrative collected in the interviews occasionally serving as a subsidiary, contextualising accompaniment to the visual analysis. Photovoice studies typically do not direct primary analytic attention towards participants' photographs, as this is said to counteract the method's principle of according voice to participants (Wang and Burris, 1997). Indeed, when considering Catalani and Minkler's (2010) metasynthesis of 37 Photovoice studies, Hergenrather et al.'s (2009) review of 31 Photovoice articles focusing on 
community change, Harper's (2002) examination of 40 photo-elicitation interviews (which introduce photographs, taken by the interviewee, into the interview context) and Sanon et al.'s (2014) review of social justice intent within 30 Photovoice studies, it would seem that Photovoice studies do not conceptualise photographs as fit for analysis. When they do, it is to reaffirm, question or bolster that which has been constructed or alluded to within linguistic text.

This study argues that directing central analytic focus towards visual discourses is to give voice to participants and does so in a manner which transcends some of the developmental and linguistic barriers that are often encountered when participants are instructed to make use of linguistic discourse. Although the participants within this study were interviewed, with each photograph producing an accompanying narrative, this article focuses on the photographs as data, with the linguistic texts occasionally serving to contextualise that of the visual. Indeed, the linguistic narratives produced within interviews were considered to be too thin for meaningful analysis, further highlighting the analytic value of visual discourses.

\section{Research design}

This study relies on a social constructionist theoretical framework, whereby all data are understood as an interpretation, susceptible to the dynamic social context in which it is situated (McKinlay and McVittie, 2008). Within social constructionism, photographs may be considered as representing and reciprocally informing the experiences of people and objects. In this sense, photographs construct reality rather than reflect it, and the notion of an objectively representable world is refuted. Meaning exists at a social rather than individual or cognitive level, with people constructing reality (Kiguwa, 2006). Visual representations of the social world then represent a legitimate, yet largely marginalised, language (Rich, 2004).

\section{Procedure}

Analysing each photograph that was produced within the Multi-Country Photovoice Project is beyond the scope of this article. Accordingly, within this study 80 of the participants' self-selected photographs were chosen for analysis. Six visual discourses were found to emerge from the data corpus. However, this study only examined the most dominant of these discourses: Humanising Capital and Unity. The six photographs selected for this article are indicative of the larger data corpus, in which more than half of the photographs depicted notions of safety, rather than that which is unsafe. In the following analysis four photographs construct safety, with the remaining two drawing on discourses that highlight the lack of safety. The faces of photographic subjects have been obscured in order to ensure anonymity.

\section{Data analysis}

VDA may be considered the theory and practice of analysing various meanings attributed to visual images. In understanding images as interrelated parts in the composition of a whole (O'Toole, 1994), VDA - as with all forms of textual discourse analysis - does not aim to 
develop a perception of a text's parts. Instead, it considers the relationship between these parts (which are referred to as possessive attributes) in connection to their whole (known as the carrier) (Kress and Van Leeuwen, 2006), as well as the relevance of that which has not been photographed (Oyebode and Unuabonah, 2013).

Although there are a number of analytic methods by which one is able to examine visual images, many of these are unable to meaningfully explore the significant effects or interpreted meaning of visual representation. Furthermore, many other kinds of analysis, such as visual content analysis, do not necessarily consider individual images, focusing instead on the data corpus as a whole (Bell, 2008). Content analyses are also ill-equipped in considering the qualitative, meaningful dimensions and nuances of culture represented within photographs (Cavanagh, 1997). For the analytic purposes of this project, VDA is especially suitable as it does not claim objectivity and is epistemologically underpinned by similar subjective meaning-making processes upon which Photovoice studies rely (Wang, 2006). Added to this is the argument that, by not depending on spoken language, participants may feel more confident in their ability to express themselves and may do so in a manner that is not susceptible to the kinds of mistranslation or developmental issues connected to linguistic expression.

The intersectional nature of a photograph's various discourses can be studied through VDA, with every visual element fit for analysis (Bell, 2008). When employing a VDA on photographs, it is thus important to look beyond the content by way of appreciating the photograph as an object within a Photovoice study. Banks (2001) argues that it is crucial that the photograph is socialised in accordance with how it might be interpreted by the viewer. This is made especially salient in the context of Photovoice, where the viewer's gaze is instrumental in engaging with a photograph's communicative message (Rich, 2004). In this regard, VDA does not necessarily attempt an understanding of the photographer's world, but rather that of the audiences (Harrison, 2004).

\section{Analytic framework}

Both O'Toole (1994) - with respect to visual art forms - and Kress and Van Leeuwen (2006) - in examining images and visual design - make use of Halliday's (1978) systematic functional model as a means of analysing visual discourses. The model relies on the notion of metafunctional principle, which posits that resources provide tools for constructing all forms of meaning. All metafunctions are then enabled through the organisation of discourse. As there is no established theoretical framework within which forms of visual communication can be analysed, Halliday presents a useful model when developing an analytical framework that is able to consider visual discourses (Kress and Van Leeuwen, 2006; O’Halloran, 2011).

The analytical framework employed within this study considers Halliday's (1978) three metafunctions. The first, or ideational, metafunction constitutes people's ideas about the world (O'Toole, 1994). In considering visual discourses, ideation offers choices with respect to how objects in relation to one another are interpreted. Within ideation, one may encounter 
experimental meaning, that is, the representation and portrayal of experiences, as well as logical meaning, which includes constructions of logical relations in the world (O'Halloran, 2011). The second metafunction, termed the interpersonal metafunction, projects enactments of social relations between the producer (photographer) and receiver (viewer) of a sign. This may include the kind of interactions between the photographic subject and its viewer. Finally, textual metafunctions refers to the capacity of visual images to form interpretable coherent texts. In this regard, different visual arrangements allow for different textual meanings (Kress and Van Leeuwen, 2006).

In interpreting the visual language used within the photographs, specific semiotic communicative strategies, which all integrate to form meaning and are outlined and drawn on by Van Leeuwen and Jewitt (2008), Banks (2001), O'Halloran (2008) and Kress and Van Leeuwen (2006), were used for the analysis in this study. These strategies included the angle and point of view of the photograph, the visual symbols that were drawn on, as well as the proximal distances between the photographic subjects.

\section{Findings and discussion}

In constructing safety, participants in this study drew predominantly on two discourses: Humanising Capital and Unity. Linguistic narratives collected in the interviews were at times featured as a contextualising component within the analysis. However, these narratives were not analysed themselves.

\section{Humanising Capital}

Within this study, the use of the Humanising Capital discourse acted to discursively humanise, or personify, constructions of financial stability. In its converse form, the discourse dehumanised depictions of low financial status. Economic prosperity was then intertwined with positive national images of Ethiopia. In considering dominant ways in which children construct safety, Humanising Capital resists notions of individualised child protection by constructing a broader economic climate as that which affects the safety of young people. Furthermore, the discourse resisted hegemonic understandings of children's notions of safety by embedding youth safety within a context of economic prosperity, a context traditionally positioned as belonging exclusively to the realm of the 'adult'.

Figure 1 depicts a woman of low socio-economic status resting against a wall. The display of the disenfranchised 'other' draws on a number of discourses, which have been well documented elsewhere (see Ortega-Alcázar and Dyck, 2011). However, it would appear that this photograph utilises an othering discourse not to tell or justify its subject's story, but rather to present her existence as a kind of societal blemish, representing a marker of lack of safety (Banks, 2001). 


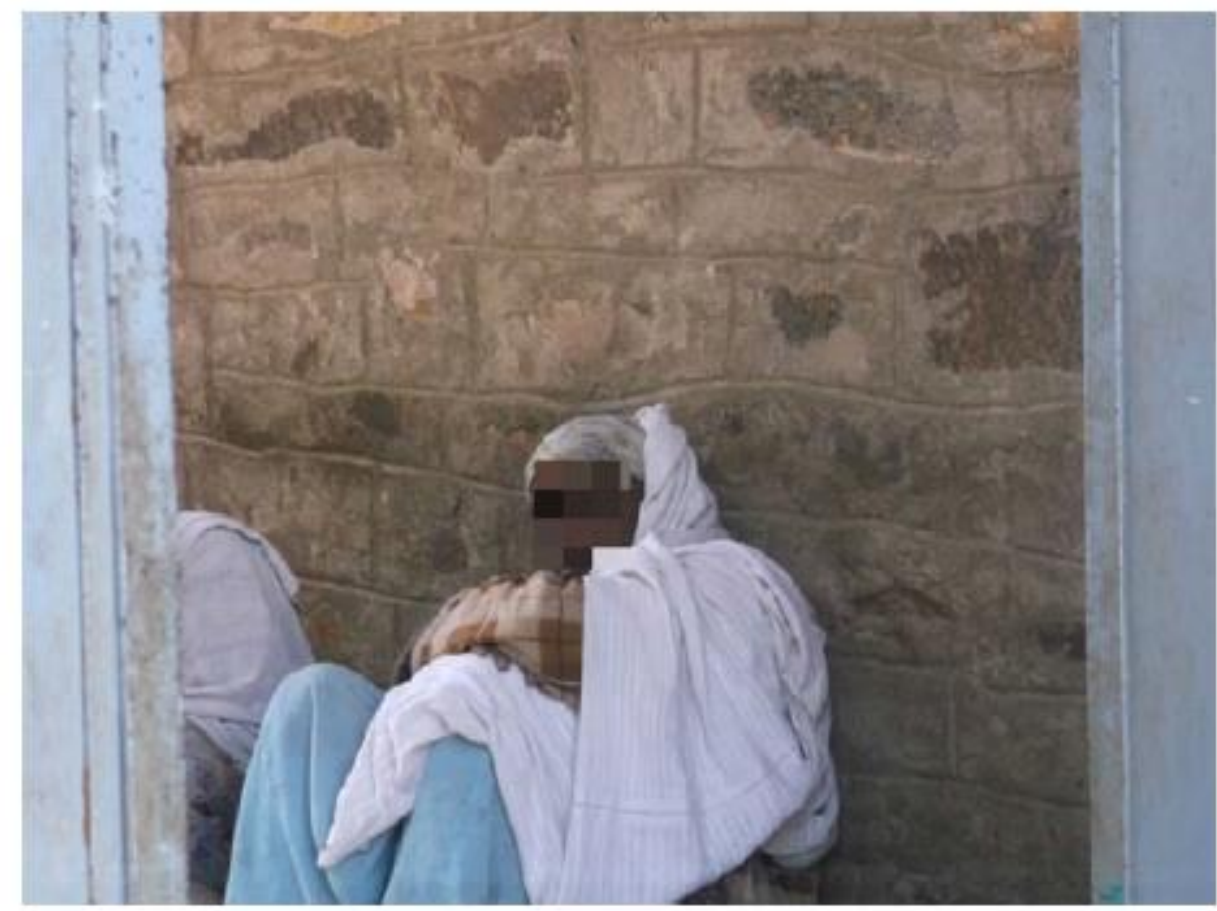

\section{Figure I. A woman rests against a wall.}

In this regard, the image acts to problematize poverty, for which the subject becomes a semiotic metaphor (O'Halloran, 2008). In considering the discourse's interpersonal metafunction, the subject is presented at eye-level so that the viewer is confronted with her image. However, it is the textual metafunction that imbues this angle with meaning. The subject's eyes are closed so that one is not made to engage with her, thereby denying her a sense of humanity (Van Leeuwen and Jewitt, 2008). The photograph does not aim to render poverty invisible; indeed, positioning a symbol of poverty as its focal point would negate such a purpose. Rather, it is the woman's subjectivity that is made invisible, and the poverty which she represents - rather than who she is - emerges as the photograph's chief communicative message.

Drawing on a similar discourse to that of Figure 1, Figure 2 ascribes economic prosperity to that of safety. With respect to the discourse's interpersonal metafunction, the subject is captured at eye-level, and her direct gaze acts to confront the viewer and demand his or her engagement and attention (Van Leeuwen and Jewitt, 2008). Her smile attempts to stabilise her humanity, avoiding the evocation of any kind of sympathy or negative affect. Considering the discourse's logical ideation metafunction builds on the viewer's interpretation, the subject is pictured selling Ethiopian coffee and is thus inserted into a nationalist narrative and she becomes fiscally engaged with one of Ethiopia's chief exports. Where the subject pictured in Figure 1 is positioned as stagnant and still, the woman featured in Figure 2 is lively and engaged. The viewers' discursive attribution of humanity within the two photographs is financially entangled, and visual symbols of economic security emerge as a discursive humanising technique. 
The direct manner in which the subject in Figure 2 engages with the viewer, while immersed within a narrative that implies her economic stability, engages an interpersonal metafunction that visually assigns her a humanity of sorts. Such humanity is then furnished with a nationalist discourse, as the subject is selling Ethiopian coffee. According to Connell (1985), insight into constructions of positive national images may be gained by examining visual discourses that make use of micro national images.

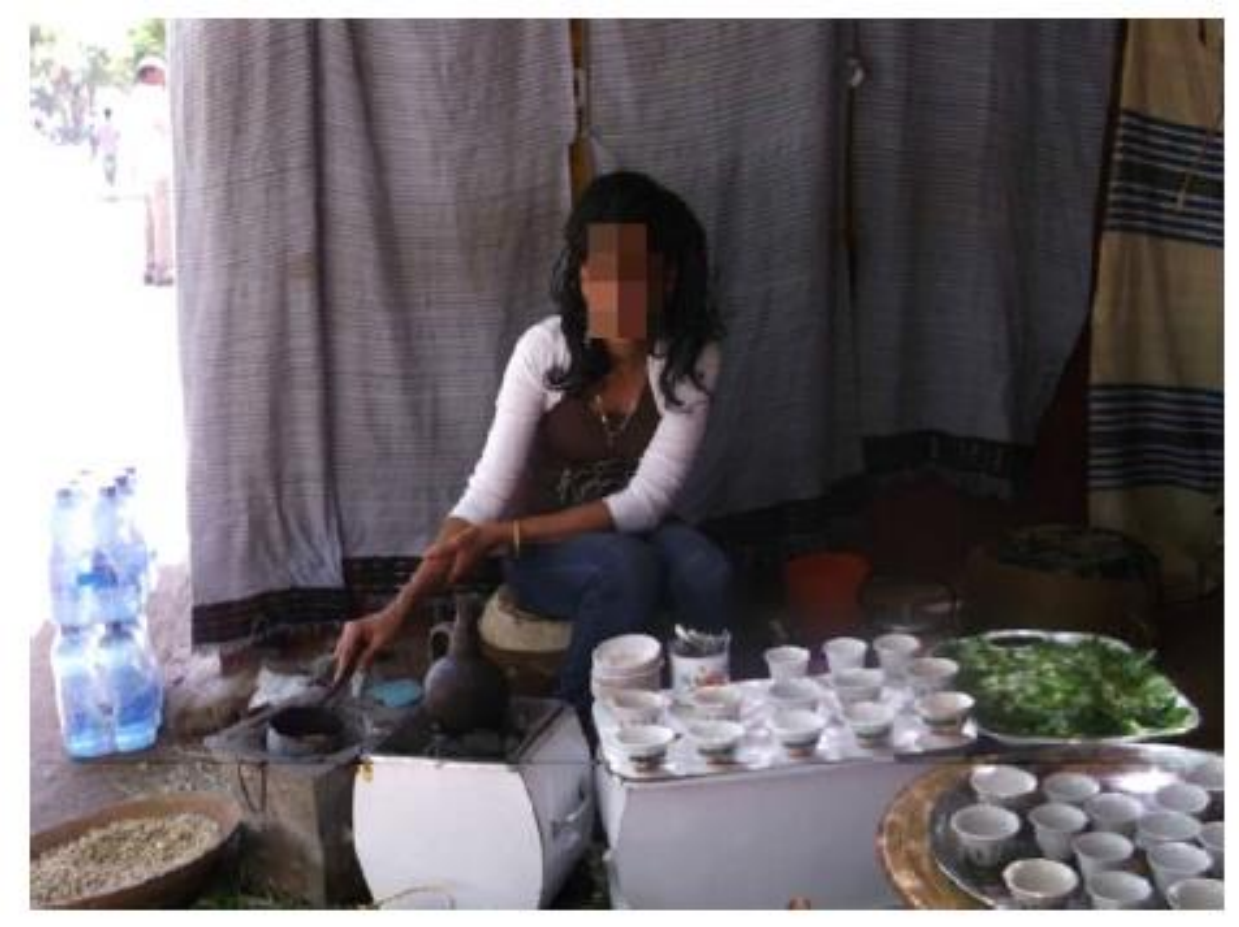

Figure 2. A woman selling coffee.

In an example of what O'Halloran (2008) refers to as semiotic mixing, Figure 3 presents an image (or rather an image of an illustration) of a nyala featured on an advertisement. It seems crucial to the image's communicative symbolism that the animal is not pictured in its habitat or embedded within any kind of narrative. Instead, the illustration of the animal is representative of its image, rather than any kind of sentience. With respect to its interpersonal metafunction, the image of an illustrative impression acts to doubly remove the viewer from the subjectivity of the animal and causes him or her to consider the nyala with respect to its commodification exclusively. Although it may be argued that a living nyala is difficult to photograph for a number of reasons, this image remains significant among participants' visual discourses that value constructions of monopolised Ethiopian symbols.

In considering this photograph's logical ideation metafunction by not utilising an image of an actual nyala - that is, a national symbol of Ethiopia, but rather its commodified illustration - the visual discourse connects the nyala's value as a symbol of safety to its ability to generate currency, and a construction emerges that attributes safety to the economy. 


\section{Unity}

The Unity discourse constructed unity, or togetherness, as that which denotes safety. Again, this discourse inserts children's constructions of safety into the realm of the adult by drawing on larger national symbols of unity. Furthermore, the use of this discourse appears to dispel notions of individualised adult protection as central to safety for children by locating such safety within unified groups of children. Indeed, almost no adults were presented within participants' visual constructions of safety.

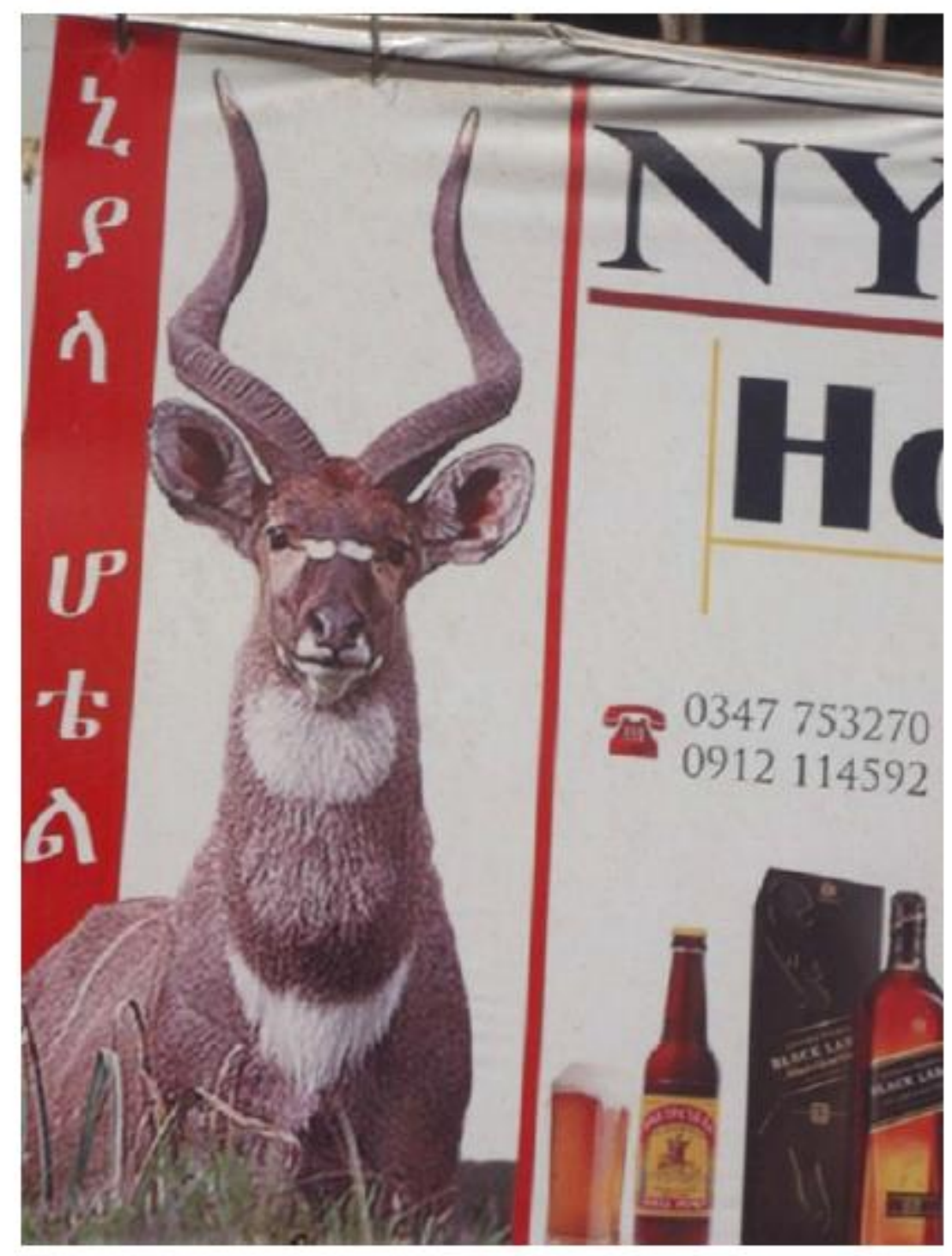

Figure 3. An advertisement for whisky depicting a nyala.

Figures 4 and 5, respectively, represent constructions of successful and failed unity. Considering the experimental ideation of Figure 4, as well as textual metafunctions, the image depicts students who are studying (visually symbolised by their workbooks), making eye contact, smiling and in close proximal distance to one another (Kress and Van Leeuwen, 
2006). A striking, and perhaps the most important, feature of the photograph's discursive construction is that safety is embedded within a context of unity.

In its textual metafunction, the depiction of a departure from the group in Figure 5 represents unity in disarray, that is, when the notion of togetherness does not hold. This image portrays a child escaping school by crawling beneath a fence, and in this sense defies the togetherness depicted in Figure 4. It would seem that, paradoxically, photographing individuals who comprise a group acts to award the subjects a sense of individuality by clearly depicting each child's face. In Figure 5, however, the subject's face is not shown. He symbolises the outcome of a group which is not unified and is therefore presented by use of roguish or disobedient constructions. Furthermore, the photograph is taken from a slightly higher angle so that the subject appears to be condemned by or of a lesser moral standing than the viewer, with the implicit interpretation that this is because his solitude is defiant of a unified group and therefore represents that which is unsafe (Van Leeuwen and Jewitt, 2008).

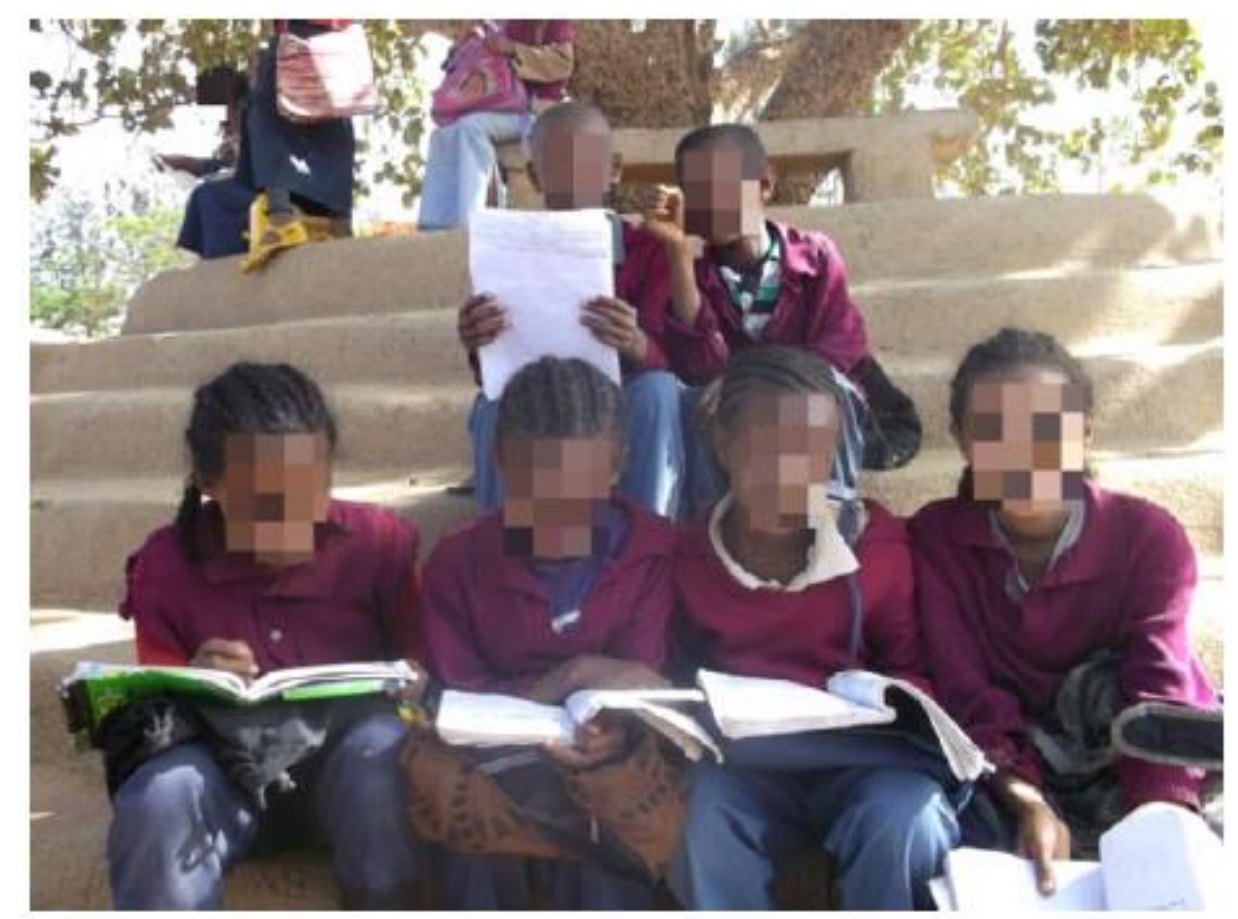

Figure 4. A group of students studying. 


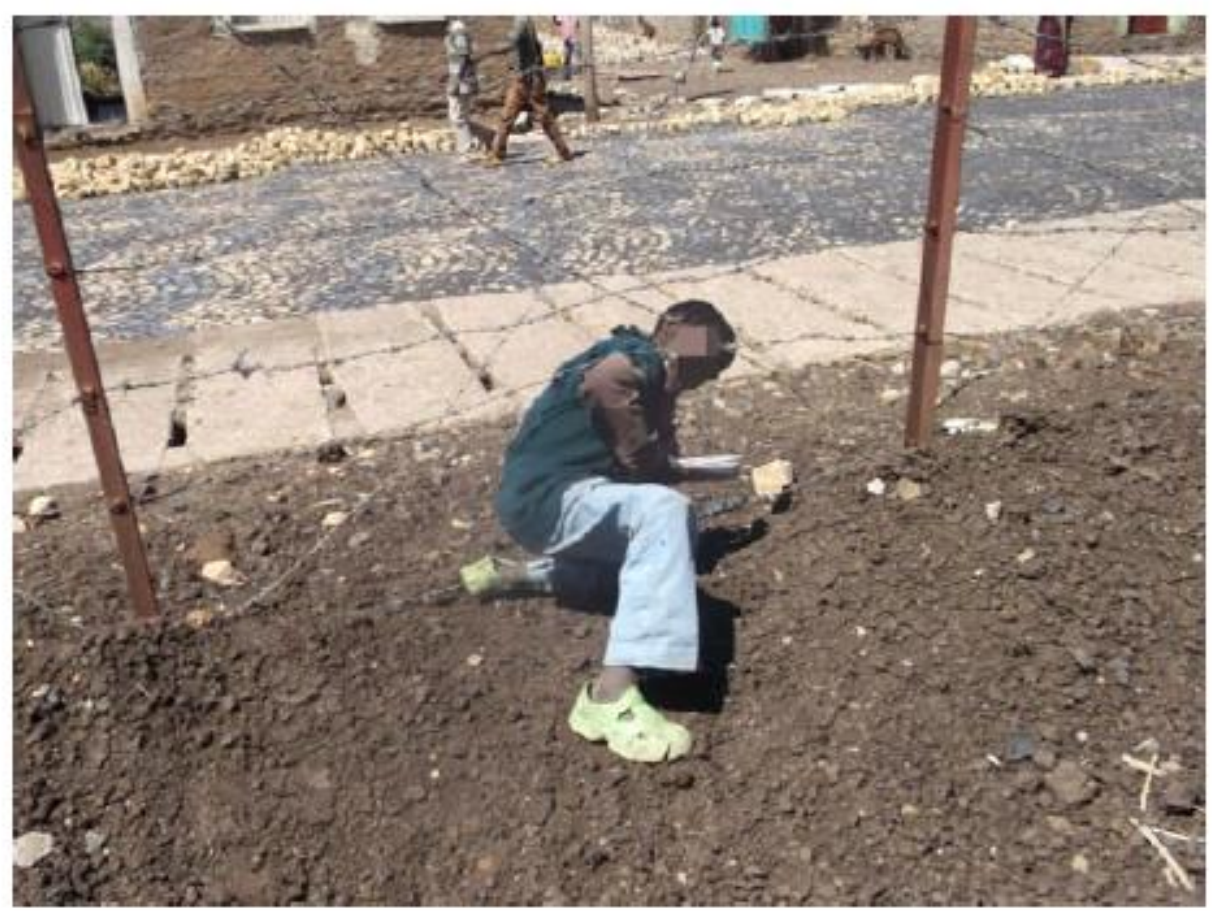

Figure 5. A child escaping from school by crawling beneath a fence.

The accent of the core discursive message of Figure 4 appears to fall on the subjects' unity. Indeed, the discourse moves beyond constructions and connotations of unified learning. Similarly, discourses attached to that of 'the bad student' are rendered more complex in the photograph's visual discourse, which does not construct improper student conduct as that which is unsafe. Rather, the subject's departure from the group becomes symbolic of lack of safety.

Through the image's textual metafunction, the students photographed in Figure 6 are depicted as displaying typical visual trappings of poverty, noted in their unclean, tattered clothing, as well as the rural school ground that serves as the photograph's backdrop. 


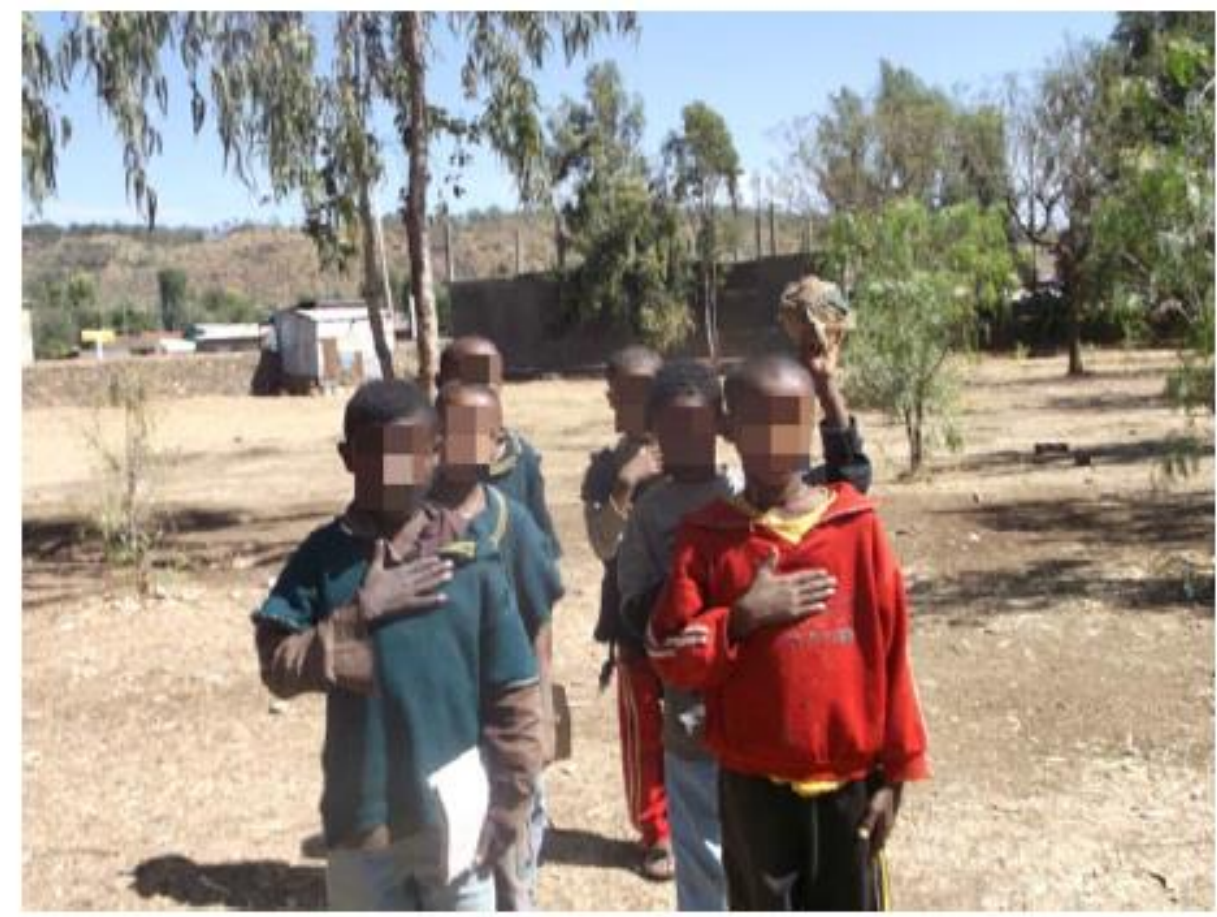

Figure 6. A group of students singing Ethiopia's national anthem.

However, by singing their country's national anthem - confirmed in an interview with the photographer - the subjects become immersed within a nationalist discourse, and their poverty is rendered secondary. Unlike the subject pictured in Figure 1, these children remove themselves from a stigmatised image of poverty by complying with the country's national codes and emerge as part of a positive, unified projection of Ethiopia. The visual discourse constructs engagement with symbols of national unity as that which is able to debase poverty as a definitive feature of one's identity.

\section{Summary and conclusion}

In this study, participants' photographs depicted an idealised construction of Ethiopia as evoking feelings of safety. Photographs drawing from the Humanising Capital discourse visually assigned humanity to photographic subjects who complied with prototypical symbols of financial stability. Ethiopia's commodifiable elements were then constructed as positive and therefore safe. By drawing on the Unity discourse, photographs constructed national and social cohesion as symbols of safety. It would seem that both discourses constructed individual feelings of safety as born from a unified and economically stable image of Ethiopia.

Western hegemonic discourses surrounding children's constructions of safety position children as passive, vulnerable entities, who are in persistent need of adult protection from a somewhat allusive danger that is incompatible with adult experience. Conversely, dominant safety discourses as they relate to young people have also constructed children as perpetrators, from whom others need protection (Suffla et al., 2012). These depictions act to 
individualise safety concerns as they are relevant for children (Harden et al., 2000; Moran et al., 1997). Within this study, however, an alternative construction of safety was utilised. Rather than individualise children's child safety discourses or position children as offenders, the Humanising Capital discourse positioned young people's constructions of safety as contained within a prosperous economic climate. Youth constructions of safety were therefore not infantilised and were introduced into the realm of fiscal 'adult' concerns. Similarly, photographs which made use of the Unity discourse constructed nationalist symbols and unified groups of children as that which denotes young people's constructions of safety. There was a notable absence of discourses constructing adults as protectors, a principal positioning within hegemonic safety discourses. It would seem that youth in this study drew upon visual modes of meaning-making that resisted the kinds of adult-directed Western discourses that dominate understandings of safety.

One may consider these findings within the context of the project's methodology, as well as Ethiopia's contemporary social and political environment. First, participants were continually made aware of their involvement in a study that was being conducted in five other countries. This was made especially salient as the lead researchers were from South Africa. Participants may have felt that their country was being comparatively showcased to an international audience, and as a result structured safety as residing within a positive national image. Perhaps visual constructions of safety within this study were intertwined with constructions of national safety because participants felt that their photographs, as well as their uniquely Ethiopian means of expression, were being scrutinised on an intercontinental platform. Future studies may wish to conduct a VDA on photographs taken by participants from other settings so that results may be compared and contrasted as a means of assessing their transferable communicative salience, and representations of safety could be considered from the perspective of children from multiple contexts. It should also be made explicit to participants that their photographs are not to be compared to those taken by others. Rather, the photographs form a kind of visual language on which they are able to draw.

With many global as well as academic assessments and projections of Ethiopia drawing primarily on discourses that highlight the country's meagre economic growth (Tafere, 2012), participants' photographs may have positioned safety in relation to economic security as a means of reappropriating dominant external depictions of Ethiopia. By constructing a unified, nationalist, stable Ethiopia, the photographs recast projections of the country along idealised, local parameters. In this sense, the photographs reflect the tension of having one's country as well as his or her national experience depicted in a particular way by others. Added to this, Ethiopia's political instability - resulting in part from Hailemariam Desalegn's appointment as Prime Minister in 2012, marking the end of Meles Zenawi's 21 years of leadership - may have contributed to the photographs' emphasis on economic stability and social unity as denotations of safety. Indeed, youth constitute a significant proportion of Ethiopia's population, and their employment directly affects the country's economy. Ethiopians enter the workforce at a far younger age than in Western contexts, perhaps resulting in the centrality of the economy within participants' constructions of safety in this study (Broussar and Tekleselassie, 2012). 
Due to funding and communication issues, participants in this study were not involved in the analysis process. In this sense, the researchers were ultimately positioned as the 'experts' rather than as facilitators, which is contradictory to the Photovoice vision of agency. Future studies should involve participants in each stage of the analysis so that their voices are not in any way obscured by those of the researchers.

It should be noted that photographs are unable to describe, generalise or affirm that which they depict (Nöth, 2011). The photograph eliminates all but one perspective of a multidimensional, dynamic image. They are likely to omit more than they include and are communicatively restricted in this sense (Rich, 2004). Such traits influence the kinds of discourses on which the image is able, as well as unable, to draw. It is for these reasons that future Photovoice studies may wish to analyse multimodal discourses, that is, language in combination with visuals integrated to create meaning, as a means of producing potentially richer data (O'Halloran, 2011). However, the purpose of this study was to highlight the value of visual discourses, which are largely ignored within social science research. Understandings of safety from the perspective of young people have relied primarily on discourses rooted in Western contexts. The results of this study highlight the need for safety research to consider other settings in which youth safety is not discursively individualised or infantilised. The study also highlights the need to harness children's voices when considering that which comprises their safety.

As MacDougall (2011) stresses, visual discourse accesses a different kind of knowledge to that of linguistic discourse. This study has highlighted how employing a VDA on the images captured in a Photovoice study is able to yield rich alternative data when working with youth who may be developmentally, culturally and linguistically removed from conventions associated with linguistic expression. It is urged that community researchers grapple with the ambiguities associated with visual analyses, especially VDA, so that participants can express themselves in a manner which is tailored to them, rather than to traditional linguistically-centred analyses.

\section{Acknowledgements}

The authors thank the project participants and research team. This is the second version which includes the reviewer's suggestions, completed 7 April 2016. The first version was submitted on 8 February 2016.

\section{Declaration of conflicting interests}

The author(s) declared no potential conflicts of interest with respect to the research, authorship, and/or publication of this article.

\section{Funding}

The author(s) disclosed receipt of the following financial support for the research, authorship, and/ or publication of this article: This work was funded by the University of South Africa. 


\section{References}

Backett-Milburn K and Harden J (2004) How children and their families construct and negotiate risk, safety and danger. Childhood 11(4): 429-447.

Banks M (2001) Visual Methods in Social Research. London: SAGE.

Bell P (2008) Content analysis of visual images. In: Van Leeuwena T and Jewitt C (eds) The Handbook of Visual Analysis. London: SAGE, pp. 10-34.

Broussar NH and Tekleselassie TG (2012) Youth employment: Ethiopia country study. International Growth Center, Working Paper Series 12/05, 21 April. Available at: http://www.theigc.org/ wp-content/uploads/2014/o9/Broussar-Tekleselassie-2012Working-Paper.pdf

Carlson ED, Engebretson J and Chamberlain RM (2006) Photovoice as a social process of critical consciousness. Qualitative Health Research 16: 836-852.

Catalani C and Minkler M (2010) Photovoice: A review of the literature in health and public health. Health Education \& Behavior 37(3): 424-452.

Cavanagh S (1997) Content analysis: Concepts, methods and applications. Nurse Researcher 4(3): 5-13.

Central Intelligence Agency (CIA) (2013) The world factbook: Ethiopia. Available at: https:// www.cia.gov/library/publications/the-world-factbook/geos/et.html (accessed 25 August 2015).

Connell RW (1985) Theorising gender. Sociology 19: 260-272.

Gant LM, Shimshock K, Allen-Meares P, et al. (2009) Effects of photovoice: Civic engagement among older youth in urban communities. Journal of Community Practice 17: 358-376.

Halliday MAK (1978) Language as Social Semiotic: The Social Interpretation of Language and Meaning. London: Edward Arnold.

Harden J, Backett-Milburn K, Scott S, et al. (2000) Scary faces, scary places: Children's perceptions of risk and safety. Health Education Journal 59: 12-22.

Harper D (2002) Talking about pictures: A case for photo elicitation. Visual Studies 17(1): 13-26. Harrison B (2004) Photographic visions and narrative inquiry. In: Bamberg $\mathrm{M}$ and Andrews M (eds) Considering Counter-narratives: Narrating, Resisting, Making Sense. Amsterdam: John Benjamins Publishing, pp. 113-136.

Hergenrather KC, Rhodes SD, Cowan CA, et al. (2009) Photovoice as community-based participatory research: A qualitative review. American Journal of Health Behavior 33(6): 686-698.

Jopson TL (2009) Imaging women and compassion in the New People's Army: The Communist Party of the Philippines' construction of its army's identity. In: Macalandag RE, Dykshoorn AN, Roldan BC, et al. (eds) An Exercise in Worldmaking 2009: Best Student Essays of 2008/o9. The Hague: Institute of Social Studies, pp. 146-159.

Kiguwa P (2006) Social constructionist accounts of intergroup relations and identity. In: Ratele K (ed.) Intergroup Relations: South African Perspectives. Cape Town, South Africa: Juta \& Company, pp. 111-136.

Kress G and Van Leeuwen T (2006) Reading Images: The Grammar of Visual Design. London: Routledge. 
MacDougall D (2011) Anthropological filmmaking: An empirical art. In: Margolis E and Pauwels L (eds) The SAGE Handbook of Visual Research Methods. London: SAGE, pp. 99-113.

McKinlay A and McVittie C (2008) Social Psychology and Discourse. London: John Wiley and Sons.

Moran E, Warden D, Macleod L, et al. (1997) Stranger-danger: What do children know? Child Abuse Review 6: 11-23.

Newbury D (2011) Making arguments with images: Visual scholarship and academic publishing. In: Margolis E and Pauwels L (eds) The SAGE Handbook of Visual Research Methods. London: SAGE, pp. 651-664.

Niesyto H, Buckingham D and Fisherkeller J (2003) Video culture: Crossing borders with young people's video productions. Television \& New Media 4: 461-482.

NöthW (2011) Visual semiotics: Key features and an application to picture ads. In: Margolis E and Pauwels L (eds) The SAGE Handbook of Visual Research Methods. London: SAGE, pp. 298-316.

O'Halloran KL (2008) Systemic functional-multimodal discourse analysis (SF-MDA): Constructing ideational meaning using language and visual imagery. Visual Communication 7(4): 444-475.

O’Halloran KL (2011) Multimodal discourse analysis. In: Hyland K and Paltridge B (eds) Companion to Discourse Analysis. London: Continuum, pp. 120-137.

Ortega-Alcázar I and Dyck I (2011) Migrant narratives of health and wellbeing: Challenging 'othering' processes through photo-elicitation interviews. Critical Social Policy 32: 106-125.

O’Toole M (1994) The Language of Displaced Art. Cranbury, NJ: Associated University Press.

Oyebode O and Unuabonah FO (2013) Coping with HIV/AIDS: A multimodal discourse analysis of selected HIV/AIDS posters in south-western Nigeria. Discourse \& Society 24(6): 810-827.

Rich M (2004) Show is tell. In: Bamberg M and Andrews M (eds) Considering Counternarratives: Narrating, Resisting, Making Sense. Amsterdam: John Benjamins Publishing, pp. 151-158.

Rich M and Chalfen R (1999) Showing and telling asthma: Children teaching physicians with visual narrative. Visual Sociology 14: 51-71.

Sanon M, Evans-Agnew RA and Boutain DM (2014) An exploration of social justice intent in photovoice research studies from 2008 to 2013. Nursing Inquiry 21(3): 212-226.

Sartre J (2006) Description. In: Manghani S, Piper A and Simons J (eds) Images: A Reader. London: SAGE, pp. 134-158.

Scott S, Jackson S and Backett-Milburn K (1998) Swings and roundabouts: Risk anxiety and everyday worlds of children. Sociology 32(4): 689-705.

Spjeldnaes IO, Moland KO, Harris J, et al. (2011) 'Being man enough': Fatherhood experiences and expectations among teenage boys in South Africa. Fathering 9: 3-21.

Suffla S, Kaminer D and Bawa U (2012) Photovoice as community engaged research: The inter-play between knowledge creation and agency in a South African study on safety promotion. Journal of Psychology in Africa 22: 517-528. 
Suffla S, Seedat M and Bawa U (2014) Reflexivity as enactment of critical community psychologies: Dilemmas of voice and positionality in a multi-country photovoice study. Journal of Community Psychology 43: 9-21.

Tafere Y (2012) Children's experiences and perceptions of poverty in Ethiopia. Young Lives, Working Paper 85, October, pp. 1-29. Available at: http://www.younglivesethiopia.org/files/workingpapers/yl_wp85_tafere_childrens_experiences_and_perceptions_of_poverty_ in_ethiopia

Van Leeuwen $\mathrm{T}$ and Jewitt C (2008) Introduction. In: Van Leeuwen $\mathrm{T}$ and Jewitt $\mathrm{C}$ (eds) The Handbook of Visual Analysis. London: SAGE, pp. 1-9.

Wang C (2006) Youth participation in photovoice as a strategy for community change. Journal of Community Practice 14: 147-161.

Wang C and Burris M (1997) Photovoice: Concept, methodology, and use for participatory needs assessment. Health Education \& Behavior 24: 369-387. 